\title{
Clinical efficacy of tirofiban combined with Solitaire stent in the treatment of acute ischemic stroke
}

\author{
Fu Xinmin*, Zhang Yang, Wang Lei, Zheng Wei, Chen Yuanyuan, Chen Guofang, Li Hongyuan, Zhang Wenwen, Dujuana and Zhang \\ Guanqun
}

Department of Neurology, Xuzhou Central Hospital, The Affiliated Xu Zhou Hospital of Medical College of Southeast University, Jiang Su 221009, China

\begin{abstract}
Objective: To explore the safety and effect of the treatment of acute cerebral infarction by microcatheter injection of tirofiban combined with SolitaireAB stent and/ or stent implantation.

Methods: For selected emergency cerebral angiogram show responsibility vascular occlusion of 120 patients with acute cerebral infarction, emergency endovascular thrombectomy, the patients were randomly divided into two groups by random number table method, thrombectomy combined with intracerebral injection of tirofiban (treatment group, 60 cases) and had only take thrombectomy (the control group, 60 cases). Baseline data from 2 groups of patients, cerebral angiography before and after surgery, hospitalization and follow-up were compared. The incidence of major adverse cerebrovascular events was compared, and the difference between the two groups was compared [90d modified Rankin scale (mRS) score 0-2 was divided into a good prognosis].
\end{abstract}

Results: There was no statistically significant difference between baseline clinical data and brain angiography in both groups $(\mathrm{P}>0.05)$. The treatment group for the treatment of cerebral infarction thrombolysis (TICI) $2 \mathrm{~b} / 3$ was higher than that of the control group $[88.3 \%(53 / 60)$ compared with $66.7 \%(40 / 60) \mathrm{P}<0.05)$. The prognosis of $90 \mathrm{~d}$ was better than that of the patients who did not use tirofiban. The prognosis of $90 \mathrm{~d}$ was better than that of the patients who did not use tirofian, and the two groups did not have the recurrence of cerebral infarction and blood vessel reconstruction. There was no statistically significant difference in postoperative bleeding between the two groups $(\mathrm{P}>0.05)$.

Conclusion: It appears to be safe and effective for endovascular treatment of acute ischemic stroke by using mechanical thrombectomy with solitaire AB stents in combination with injection of tirofiban through microcatheter. But the indications of operation should be strictly grasped.

Acute cerebral infarction is a common disease with high morbidity and mortality. Early thrombolytic therapy is one of the most effective methods to reduce the mortality and disability of acute cerebral infarction. The purpose of thrombolysis is to open the occlusion vessels in time, to save the ischemic penumbra neurons, which is generally believed to be the best time for intravenous thrombolysis in 4.5 hours after the onset of acute cerebral infarction. However, the efficiency of the revascularization is only about $30 \%$, and the good prognosis is only about $15 \%$, and the time window is only 4.5 hours. Clinically most patients exceeding intravenous thrombolysis time window, we try to have arterial thrombolysis and endovascular thrombectomy for ischemic stroke 8 to 12 hours after a patient was last known to be well plus standard medical therapy. Arterial injection of low dose tirofiban by microcatheter, had less bleeding risk, achieve better clinic effect, combined with endovascular thrombectomy when necessary, using brain artery stent, stents implantation to open occlusion of cerebral arteries, cerebral blood supply is resumed as soon as possible, reduce the scope of cerebral infarction, and reduces the sequela of cerebral infarction or death. In the treatment of atherosclerotic cerebral infarction, vascular endothelial injury and platelet activation are easy to occur, which leads to the formation of in-situ thrombosis and the reocclusion of blood vessels. The incidence of intracranial atherosclerosis in Asian population is higher.

Whether the intracranial occlusion vessels can be reconnected in time is closely related to the prognosis of patients with acute cerebral infarction. In recent years, our hospital application SolitaireAB stent mechanical thrombectomy combined with injection of low dose tirofiban by microcatheter in treatment of acute cerebral infarction, achieved good effect, now report as follows.

\section{Materials and methods}

A total of 120 patients with acute cerebral infarction who were selected for the complete occlusion of the blood vessel after the emergency cerebral angiography were selected from the study subjects from March 2012 to April 2016. Inclusion criteria: aged 18-86; Clinical diagnosis of acute cerebral infarction, and the national institute of health stroke scale (NIHSS) $>3$, lasted more than 30 min; Patients with the onset time of $8 \mathrm{~h}$ (the posterior circulation is not more than $12 \mathrm{~h}$ according to the situation); CT or MRI excluded cerebral hemorrhage or other obvious intracranial diseases; Image confirmed (CTA/MRA/ DSA) intracranial artery occlusion: the internal carotid artery, the M1/ M2 segment of the cerebral artery, the anterior cerebral artery A1/ A2, the basilar artery, the vertebral artery V4 segment, the posterior cerebral artery P1 segment; Patients or family members have signed informed consent. Exclusion criteria: NIHSS score less than 3 or

Correspondence to: Fu Xinmin, Department of Neurology, Xuzhou Central Hospital, The Affiliated XuZhou Hospital of Medical College of Southeast University, Jiang Su 221009, China, E-mail: 54448096@qq.com

Key words: acute ischemic stroke, solitaire AB stent, endovascular thrombectomy, tirofiban

Received: February 24, 2018; Accepted: March 05, 2018; Published: March 09, 2018 
NIHSS score significantly improved; MRS score was $>2$ before the stroke. Patients with a life expectancy of less than 3 months or unable to complete the study for other reasons; DSA inspection taboo, serious contrast agent allergy or iodine contrast agent absolute taboo; Women during pregnancy or lactation; Unable to complete the study due to mental illness; Uncontrolled hypertension: pre-treatment systolic blood pressure $>220 \mathrm{mmHg}$ or diastolic pressure greater than 110 mmHg; Having a history of hemorrhagic cerebrovascular disease or bleeding tendency; Important organ dysfunction or failure; The patient or family member did not sign the informed consent. Among the 120 patients with acute ischemic stroke, 59 were male and 61 were female. Age 27 86, average 57.4 years old. Will be selected by random number table method in patients were randomly divided into two groups: control group pure cerebral artery stents should, a total of 60 cases, treatment group stent should jointly by the micro catheter cerebral artery injection for class, had a total of 60 cases.

\section{Interventional therapy and medication methods}

After patients admitted to hospital as soon as possible through the green channel except complete preoperative associated with contraindications, signed informed consent form at the same time, both to control blood pressure, maintain water electrolyte and acidbase balance treatment of preoperative preparation, etc. Emergency line head CT scan to rule out bleeding, head CT did not see obvious lowdensity lesions at the same time, some patients with cranial MRI+DWI and MRA can or head CTA examination, clinical consideration immediately after cerebral artery occlusion DSA and comprehensive endovascular treatment, as shown in Figure 1.

The patient was given a supine position before operation, and the anesthesia was determined according to the patient's degree of coordination. If the patient can cooperate, only local anesthesia is given. If the patient is in poor state of consciousness, it is easy to cooperate with the general anesthesia. Most patients adopt endovascular treatment under local anesthesia, using modified Seldinger technique puncture femoral artery on the right or the left femoral artery, in $6 \mathrm{~F}$ arterial sheath pipe, using imaging tube first whole cerebral angiogram

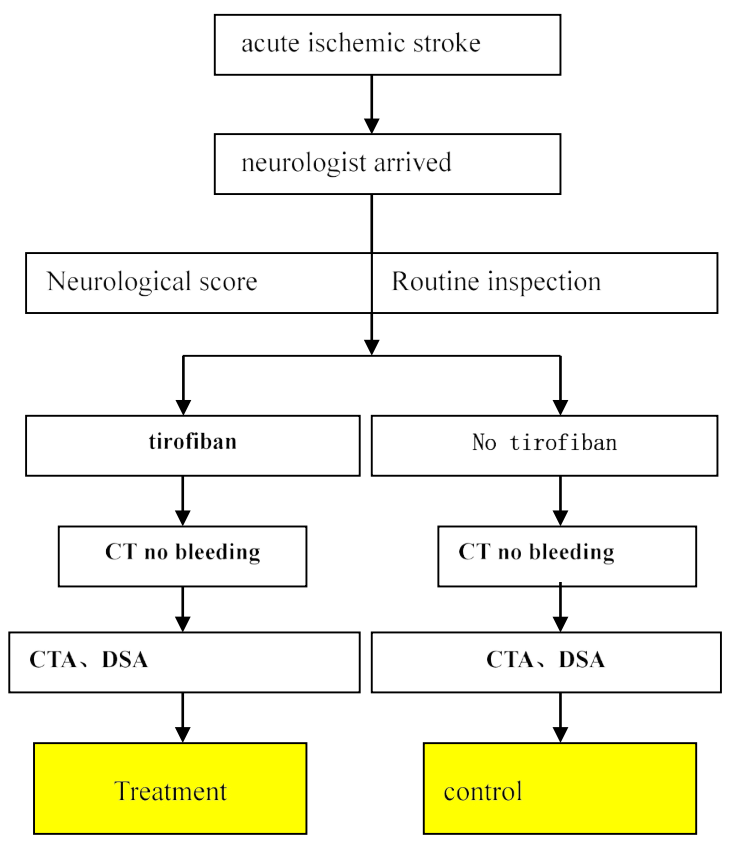

Figure 1. A process of green passage in stroke collateral compensatory situation of clear and to assess the lesion site. If blood vessel occlusion or subtotal occlusion is found and the indications are consistent with endovascular treatment indications, intravascular treatment is tried, as shown in Figure 2.

Peripheral venous heparinization, heparin dosage is $60 \mathrm{U} / \mathrm{Kg}$, and $6 \mathrm{~F}$ guided catheter tip is placed into the responsible artery (vertebral artery or carotid artery) under the guidance of hyper slip guide wire. On the road map, rebar-18 or rebar-27 (EV3 Inc, USA) microcatheter tip reaches the distal end of the thrombus, and the microcatheter is clearly defined in the vascular cavity, as shown in Figure 3.

The microcatheter was treated with contact antithrombotic therapy for tirofiban. The microcatheter was retracted, the head was buried in the thrombus, and it continued to be injected into tirofiban, and then the microcatheter was withdrawn to the proximal end of the thrombus, and then it was injected into tirofiban, and the total amount was 0.2 $\mathrm{ug} / \mathrm{kg} / \mathrm{min}$. After $15 \mathrm{~min}$, the catheter was reexamined, and if the artery of the lesion was found to be still not open, then the stenting was performed, while the peripheral vein continued to be pumped into tirofiban $0.1 \mathrm{ug} / \mathrm{kg} / \mathrm{min}$.

Endovascular thrombectomy: microcatheter through the occluded artery, micro catheter trace imaging showed again in the arterial lumen, distal blood flow is good, as shown in Figure 4 . Then, according to the diameter of the lesion, the Solitaire AB $4 \mathrm{~mm} \times 20 \mathrm{~mm}$ or SolitaireAB 6 $\mathrm{mm} \times 20 \mathrm{~mm}$ (EV3, Inc, USA) was placed in the lesion, as shown in Figure 5 . The stent and microcatheter were then removed simultaneously to the guide tube, and the catheter was removed from the body, and the thrombus extracted by the Solitaire stent was examined, as shown in Figure 6. If necessary, take the bolt several times, and then check the angiogram to see if the blood vessel is Complete recanalization after the thrombus is completed (Figure 7).

If the angiography showed that the vessel wall was basically smooth, and the main branches were smooth, the flow rate and flow rate were basically normal, as shown in Figure 7, thrombectomy was completed.

After operation, low molecular weight heparin calcium (0.4 $\mathrm{mL} / \mathrm{d})$ subcutaneously injected and given to nimoton $(5 \mathrm{~mL} / \mathrm{h})$ to prevent thrombosis and cerebral vasospasm, or to continue pumping $6 \mathrm{ml} / \mathrm{h}$ tirofiban. Control systolic pressure at 110 140 $\mathrm{mmHg}$. If $\mathrm{rt}-\mathrm{pa}$ patients were given rt-pa in preoperative or intraoperative treatment, oral aspirin should be taken for 24 hours after the thrombectomy, $100 \mathrm{mg} / \mathrm{d}$, clopidogrel $75 \mathrm{mg} / \mathrm{d}$ for a month, and then long-term oral aspirin for $100 \mathrm{mg} / \mathrm{d}$. If the patient had no rt-pa or arterial thrombolytic treatment, aspirin and clopidogrel were immediately given either oral or nasal feeding. If the balloon dilation and stent implantation, takes $100 \mathrm{mg} / \mathrm{d}$ of aspirin, clopidogrel $75 \mathrm{mg} / \mathrm{d}$ a total of 3 to 6 months, and intraoperative give load $300 \mathrm{mg}$ of aspirin and clopidogrel 300 through anus, or intraoperative and postoperative continuous pumping for class $6 \mathrm{ml} / \mathrm{h}$ had a total of 6 hours, 3-6 months after $100 \mathrm{mg} / \mathrm{d}$ of aspirin or clopidogrel $100 \mathrm{mg} / \mathrm{d}$ take a long time.

\section{Observation project}

(1) postoperative cerebral infarction and thrombolytic treatment classification (TICI), postoperative TICI grading $<2 \mathrm{~b}$ was defined as cerebral perfusion. (2) after interventional therapy, the head MRI+ DWI+MRA was reviewed, and some patients underwent cephalic CTA examination to analyze the recirculation of cerebral vessels. (3) major adverse cerebrovascular events in the hospital and $30 \mathrm{~d}$ after discharge, including: death, non-fatal re-infarction, target blood vessel blood transport and reconstruction. The NIHSS scores were compared before 


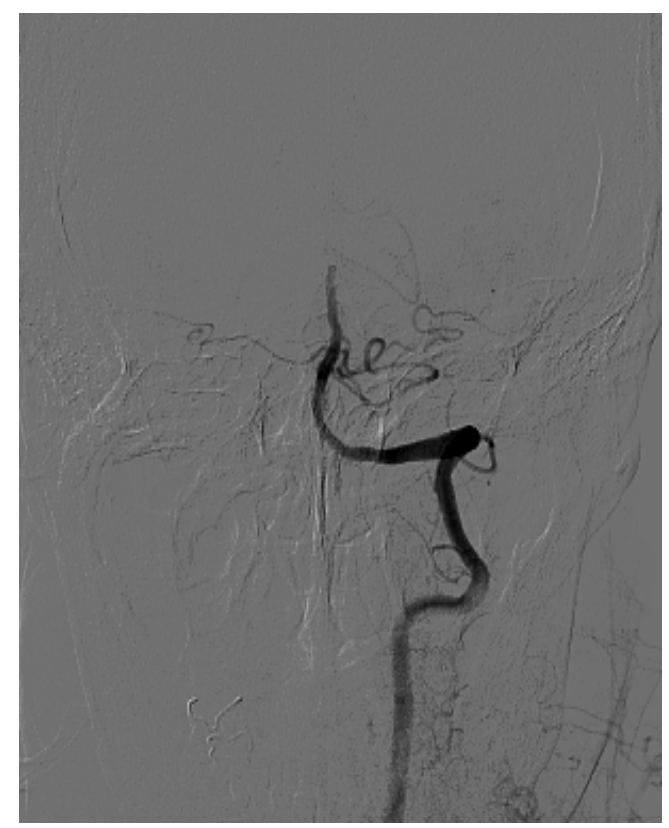

Figure 2. An occlusion of the distal end of the preoperative basilar artery

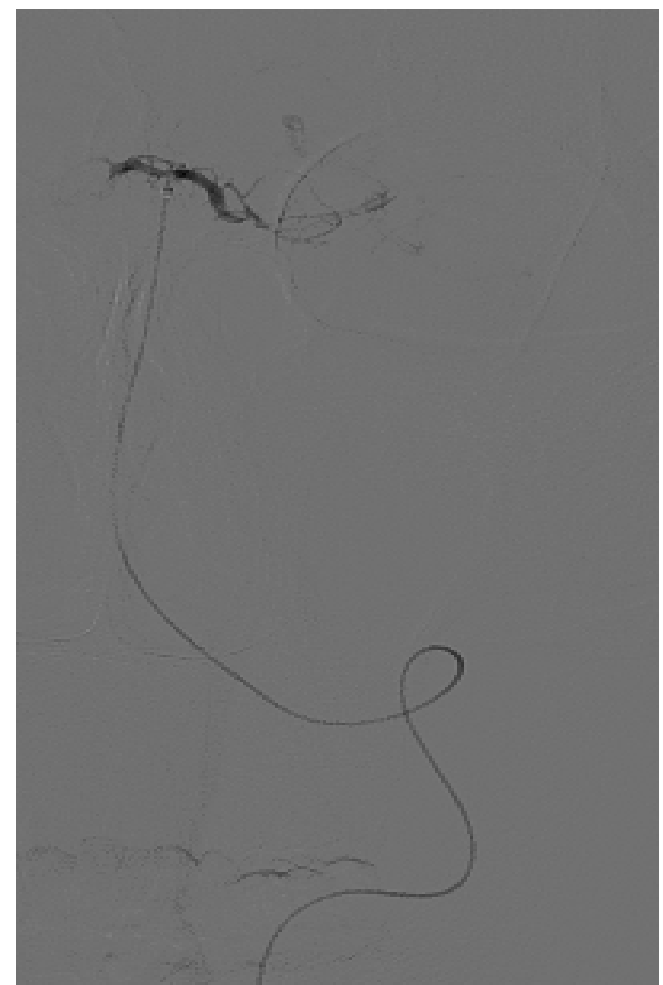

Figure 3. Microcatheter tip reaches the distal end of the thrombus, and the microcatheter is clearly defined in the vascular cavity

and after surgery. After discharge, the follow-up method was telephone inquiry and outpatient consultation. (4) incidence of hospital bleeding events. (5) three months after surgery, the head MRI+MRA was reviewed, and modified Rankin scale (mRS) was used to assess the prognosis of patients.

\section{The statistical analysis}

SPSS21.0 was used for statistical analysis, and the measurement data was expressed by $\mathrm{x} \pm \mathrm{s}$. $\mathrm{T}$ test was used for statistical analysis, and
$\mathrm{P}<0.05$ The differences were statistically significant. The counting data is expressed in frequency and percentage; X2 test was used for comparison between groups. If there are theoretical frequencies $<5$, precise probability method is adopted; If the difference between multiple groups was statistically significant, the comparison between the two groups was based on the $\mathrm{x} 2$ segmentation method. $\mathrm{P}<0.05$ The differences were statistically significant.

\section{Result}

The general clinical data: the comparison of two groups of patients with clinical baseline data are shown in Table 1 , in gender, age, clinical features, cerebral artery lesion characteristics, stroke to femoral artery puncture time, intravenous thrombolysis time, placing stents differences had no statistical significance $(\mathrm{P}>0.05)$.

The therapeutic effect of interventional therapy (Table 2), the proportion of patients with postoperative cerebral infarction (TICI) $2 \mathrm{~b} / 3$ was higher than that in the control group $[88.3 \%(53 / 60)$ and $66.7 \%(40 / 60) \mathrm{P}<0.05)$. The prognosis of $90 \mathrm{~d}$ was better than that of the patients who did not use tirofian, and the two groups did not have the

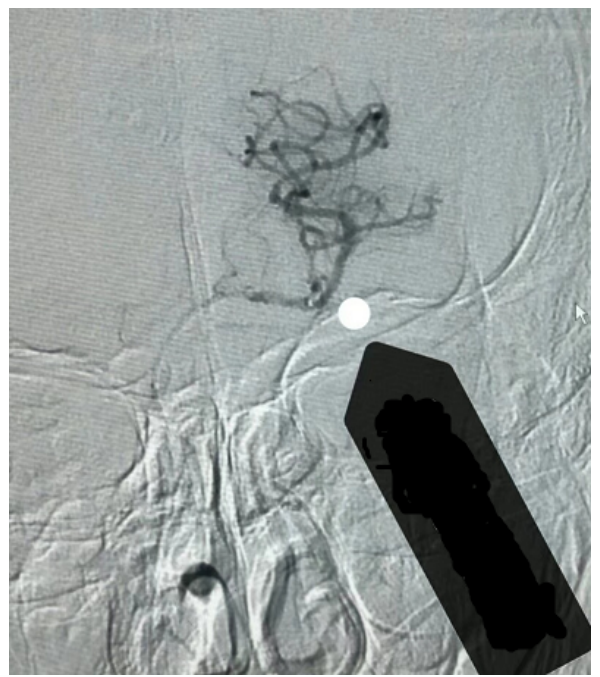

Figure 4. Microcatheter imaging showed good blood flow in the distal end of the artery

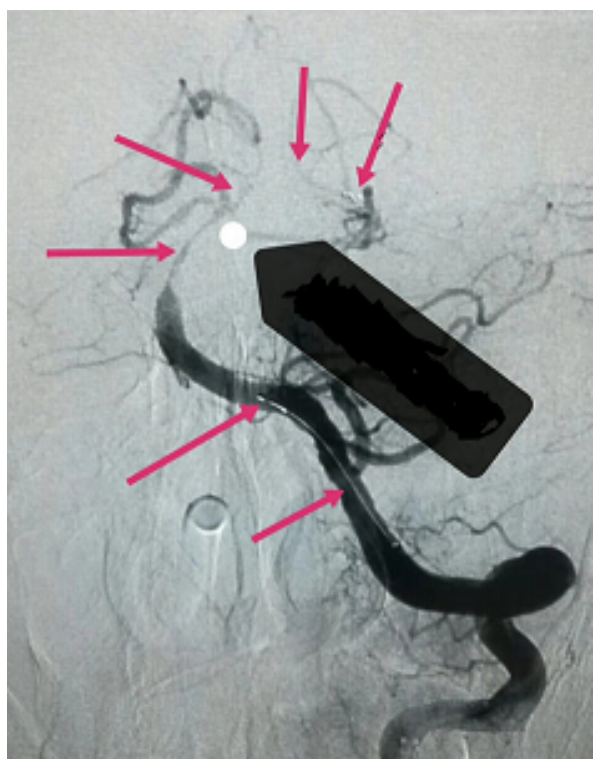

Figure 5. Stent was carried out in the lesion 
recurrence of cerebral infarction and blood vessel reconstruction. No symptomatic intracranial hemorrhage occurred in all patients. There was no statistically significant difference in postoperative bleeding between the two groups $(\mathrm{P}>0.05)$. During hospitalization and followup, 3 patients died in the control group, 2 patients died of cerebral hernia in 2 days after thrombectomy, and 1 case died of pulmonary infection 10 days after thrombectomy. In the treatment group, 2 patients died after the thrombectomy, 1 patient died of cerebral hernia in 3 days after thrombectomy, and 1 patient died of lung infection after the second half of the thrombectomy.

Hemorrhage: 7 cases (11.7\%) of postoperative cerebral hemorrhage occurred in the control group, including 1 case of symptomatic cerebral

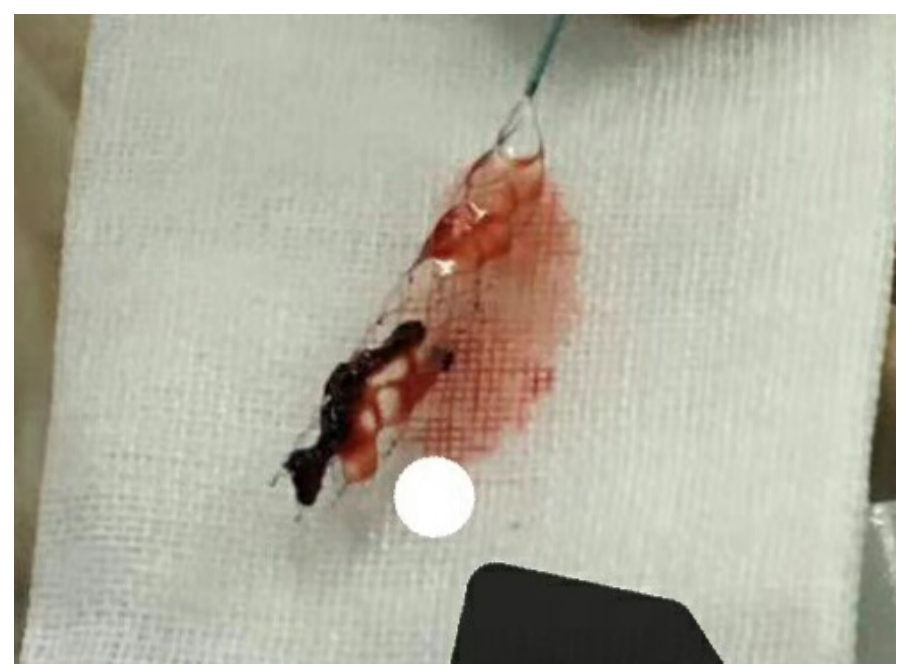

Figure 6. Stent removed thrombus

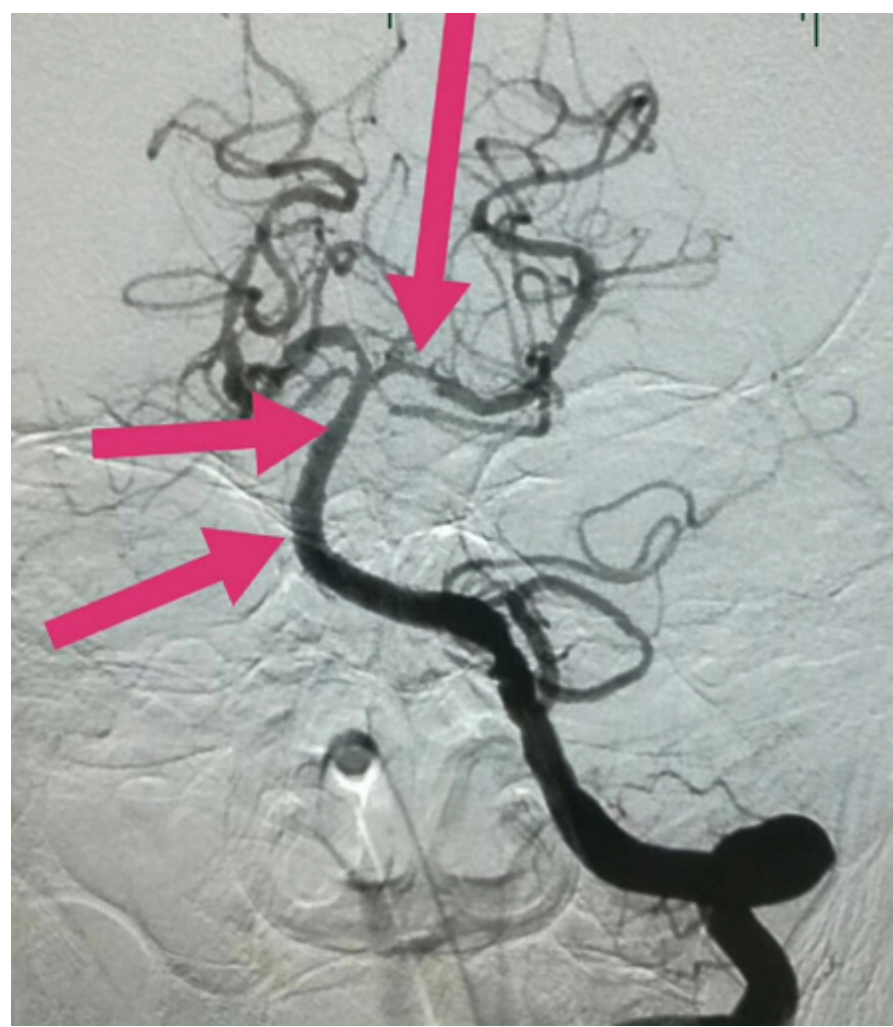

Figure 7. Basilar artery and its branches were unobstructed
Table 1. Comparison of clinical baseline data of two groups of patients

\begin{tabular}{|c|c|c|c|}
\hline Item & $\begin{array}{c}\text { Treatment } \\
(\mathrm{n}=60)\end{array}$ & $\begin{array}{c}\text { Control } \\
(n=60)\end{array}$ & $\mathbf{P}$ \\
\hline Age $^{\mathrm{a}}$ & $56.4 \pm 13.3$ & $58.1 \pm 15.6$ & 0.39 \\
\hline Male $^{\mathrm{b}}$ & $42(70.0)$ & $45(75.0)$ & 0.45 \\
\hline Hypertension $^{\mathrm{b}}$ & $36(60.0)$ & $38(63.3)$ & 0.78 \\
\hline Diabetes $^{\mathrm{b}}$ & $13(21.6)$ & $10(16.7)$ & 0.65 \\
\hline Smoking ${ }^{\mathrm{b}}$ & $24(40.0)$ & $21(35.0)$ & 0.47 \\
\hline Family Stroke History ${ }^{\mathrm{b}}$ & $9(15.0)$ & $7(11.7)$ & 0.39 \\
\hline $\mathrm{Tia}^{\mathrm{b}}$ & $5(0.08)$ & $4(0.07)$ & 0.23 \\
\hline Systolic Blood Pressure (Mmhg) ${ }^{\mathrm{a}}$ & $130 \pm 14.6$ & $139 \pm 16.4$ & 0.32 \\
\hline Diastolic Blood Pressure (Mmhg) ${ }^{\mathrm{a}}$ & $75 \pm 12.2$ & $74 \pm 11.9$ & 0.31 \\
\hline LDL-C $(\mathrm{Mmol} / \mathrm{L})^{\mathrm{a}}$ & $2.4 \pm 1.2$ & $2.5 \pm 0.9$ & 0.23 \\
\hline Creatinine $(\mathrm{Umol} / \mathrm{L})^{\mathrm{a}}$ & $72 \pm 14.9$ & $76 \pm 15.7$ & 0.34 \\
\hline Blood Glucose At Admission $(\mathrm{Mmol} / \mathrm{L})^{\mathrm{a}}$ & $9.4 \pm 3.4$ & $8.8 \pm 3.6$ & 0.32 \\
\hline Intravenous Thrombolysis $^{\mathrm{b}}$ & $17(28.3)$ & $19(31.6)$ & 0.86 \\
\hline The Baseline Nihss ${ }^{\mathrm{a}}$ & $14.3 \pm 6.4$ & $15.6 \pm 7.1$ & 0.39 \\
\hline Atrial Fibrillation $^{\mathrm{b}}$ & $16(26.7)$ & $18(30.0)$ & 0.16 \\
\hline Coronary Heart Disease $^{\mathrm{b}}$ & $9(15.0)$ & $7(11.7)$ & 0.14 \\
\hline Middle Cerebral Artery Occlusion ${ }^{\mathrm{b}}$ & $29(48.3)$ & $27(45.0)$ & 0.19 \\
\hline Internal Carotid Artery Occlusion $^{\mathrm{b}}$ & $5(8.3)$ & $6(10.0)$ & 0.27 \\
\hline Vertebral Basilar Artery Occlusion ${ }^{\mathrm{b}}$ & $26(43.3)$ & $27(45.0)$ & 0.32 \\
\hline $\begin{array}{l}\text { Duration of Stroke to Femoral Artery } \\
\text { Puncture }^{\mathrm{a}}\end{array}$ & $4.6 \pm 3.1$ & $4.3 \pm 2.8$ & 0.33 \\
\hline Number of Stents (Pieces) ${ }^{\mathrm{a}}$ & $0.26 \pm 0.02$ & $0.23 \pm 0.01$ & 0.36 \\
\hline Stent Diameter $(\mathrm{Mm})^{\mathrm{a}}$ & $5.34 \pm 0.12$ & $5.21 \pm 0.11$ & 0.56 \\
\hline Stent Length $(\mathrm{Mm})^{\mathrm{a}}$ & $25.24 \pm 1.2$ & $24.3 \pm 1.4$ & 0.45 \\
\hline
\end{tabular}

Note: The treatment group, control group; AIS: Acute ischemic stroke, LDL-C: Low density lipoprotein cholesterol, TICI: Cerebral infarction thrombolysis treatment of classification, 1 $\mathrm{mmHg}=0.133 \mathrm{kPa}$. A is represented by $\mathrm{x} \pm \mathrm{s}$, and $\mathrm{b}$ is expressed as an example (\%)

Table 2. Comparison of therapeutic effect of patients in 2 groups

\begin{tabular}{|c|c|c|c|}
\hline & $\begin{array}{c}\text { Treatment } \\
(\mathrm{N}=60)\end{array}$ & $\begin{array}{l}\text { Control } \\
(\mathrm{N}=60)\end{array}$ & $\mathrm{P}$ \\
\hline $\mathrm{TICI} 2 \mathrm{~b} / 3^{\mathrm{a}}$ & $53(88.3)$ & $45(73.3)$ & 0.036 \\
\hline Symptomatic Intracranial Hemorrhage $\mathrm{a}^{\mathrm{a}}$ & $2(3.3)$ & $3(5.0)$ & 0.45 \\
\hline Reocclusion $^{\mathrm{a}}$ & $1(1.7)$ & $5(8.3)$ & 0.019 \\
\hline Stent Thrombosis ${ }^{\mathrm{a}}$ & $0(0)$ & $1(7.1)$ & 0.18 \\
\hline $90 \mathrm{dmrs} 0-2^{\mathrm{a}}$ & $37(61.7)$ & $27(45.0)$ & 0.024 \\
\hline Nihss $^{\mathrm{a}}$ & $4.39 \pm 3.24$ & $6.26 \pm 4.10$ & 0.048 \\
\hline Mortality $^{\mathrm{a}}$ & $4(6.7)$ & $6(10.0)$ & 0.15 \\
\hline
\end{tabular}

Note: The treatment group, the control group, A takes the example (\%)

hemorrhage. In the treatment group, 8 patients (13.3\%) had post thrombectomy cerebral hemorrhage, including 2 cases of symptomatic cerebral hemorrhage. One patient had cerebral vascular interlayer, 1 patient had hematoma in the puncture site, and no complications related to other neurointerventional techniques.

\section{Discussion}

In the treatment of acute cerebral infarction and intravascular interventional therapy or intravenous thrombolytic therapy, even after the infarcted arterial blood flow is restored to the level, there are still some patients with brain cell level reperfusion. This makes the criminal's blood vessels pass through, but it does not reach the level of the organization's true meaning of reperfusion. The clinical manifestation is that the prognosis is not ideal after the successful recirculation of intracranial occlusion, and the neurological symptoms are progressive.

The main mechanisms of cerebral infarction during acute cerebral infarction include microcirculation embolization of brain tissue, 
microcirculation ischemia reperfusion injury, microvascular structure destruction, etc. In recent years, after reperfusion therapy for acute cerebral infarction infarction microcirculation disorder, a lot of research on domestic and foreign scholars, these studies have focused on how to reduce and prevent the microcirculation embolism and blocking of reperfusion injury pathways, such as oxygen free radicals shed, neutrophil aggregation block capillaries, cells and interstitial edema, microvascular spasm, endothelial dysfunction and other aspects of brain protection.

The microcirculation platelets play a key role in the process of the early formation of blood clots, therefore, in theory the platelet membrane glycoproteins II b/III a receptor antagonist can alleviate micro thrombus formation and its effect on the subsequent damage to the microcirculation, so as to improve the level of brain tissue reperfusion. Cerebral angiogram showed lesions for high load thrombus disease criminals, high rate of stent thrombosis, active application of platelet membrane glycoproteins II / 1 b I a receptor antagonist can reduce the possibility of recanalization of blood vessels occlusion again, improve the level of brain tissue reperfusion effect.

In the treatment of atherosclerotic cerebral infarction, vascular endothelial injury, platelet activation and reocclusion [1] are easy to occur. The incidence of intracranial atherosclerosis in Asian populations is higher [2]. Previous studies have also found that in patients with acute cerebral infarction, there is a high probability of re-occlusion in the treatment of mechanical thrombolysis, which is $16 \% \sim 18 \%$ [3]. Therefore, it is of great clinical significance to find a treatment method that can prevent the reocclusion of blood vessels after mechanical thrombolysis.

Tirofiban is a selective platelet glycoprotein II b/III antagonist, can inhibit platelet aggregation, thereby preventing atherosclerosis cerebral infarction of result of in situ thrombosis after occlusion. At the same time, the safety of tirofiban for acute cerebral infarction has been verified by the safety test of acute ischemic stroke [4].

The lesion vessels of acute cerebral infarction tend to have high thrombus load and more atherosclerotic plaque fragments, and drug therapy has certain limitations in these aspects. Cerebrovascular stent should mainly apply in the criminal or larger diameter and responsibility of intracranial artery vascular thrombosis load has been completely isolated patients, can directly pull out suspended in stent thrombosis and to bolt material (lesion location release of inflammatory mediators and vascular active substance). Although through mechanical in treating acute cerebral infarction, 90 patients with 90d prognosis has been improved a lot [5], but there are still some patients cannot succeed because of vessels and result in poor prognosis. Previous studies have reported that the recirculation rate of the responsible blood vessels after intravascular therapy is $66 \%$ to $76 \%$, while that of $90 \mathrm{~d}$ has a good prognosis of $32.6 \%$ to $43.7 \%$ [6]. In this study, the vascular recirculation rate of patients in the treatment group was $88.3 \%$ and the functional rate was $61.7 \%$.

We hypothesized that in the treatment of endovascular thrombectomy, most of the reocclusion of the vessels was related to the formation of in-situ thrombosis. When in the process of mechanical should occur when blood vessels occlusion again, again within arteries after should give had class for low doses, can prevent the happening of the blood vessels to block, which is supported by the results. Kim, et al. [7] reported that intra-arterial treatment of intra-arterial intravascular therapy could reduce the infarct area, improve reperfusion, and reduce the occurrence of reocclusion.
In patients with acute cerebral infarction were took the treating therapy, high incidence of vascular occlusion again, and in small doses of application for arteries can prevent vascular occlusion occurs again, at the same time can improve the prognosis of patients. This study within a certain time window in addition to the feasible vein thrombolysis drug, can also according to patients' informed consent after cerebral angiogram, intraoperative according to cerebrovascular disease condition, analyzed the responsibility of the cerebral infarction lesions artery occlusion, selecting vascular treatment for arterial thrombolysis [8], endovascular thrombectomy with vascular balloon angioplasty, cerebrovascular stent implantation and combined use of these methods $[9,10]$.

Endovascular thrombectomy can quickly restore blood flow, improve clinical outcomes, in particular time is to brain, the earlier opened early recovery of the cerebral blood flow, the greater the chance of patients recover, the endovascular treatment technology has been more and more attention. Know about the safety of SolitaireAB support extraction for existed controversy, but large-scale randomized controlled clinical trials proved SolitaireAB stents compared bolt extraction for pure thrombolysis can improve the prognosis of patients with more $[6,10,11]$. This group of 120 patients with Endovascular thrombectomy or if necessary to obtain good results after stent implantation, confirmed the same method can really benefit the patients with acute ischemic stroke. Intracerebral hemorrhage is one of the major complications of acute ischemic stroke thrombolysis or intravascular therapy. Intraoperative bleeding more and take bolt installation vessel wall damage, the reason of postoperative hemorrhage may have reperfusion, thrombolysis drug use and combination antiplatelet and anticoagulant therapy [12]. In this group, there were 8 cases of hemorrhage transformation in the treatment of tirofian, and the bleeding rate was about $13.3 \%$, which was not significant compared with the control group. It is in controllable range that the indications and perfect postoperative management of thrombolysis and arterial thrombolysis are strictly controlled. Combined with the literature and our experience, the time is too long having super time window, brain CT showed low density change or MRI has clear infarct, preoperative blood pressure high (systolic blood pressure >180 MMHG, diastolic blood pressure >100 MMHG) of stroke patients if treated with thrombolysis or bolt prone to cerebral hemorrhage [13]. Although the effect of endovascular thrombectomy has been confirmed, there are still differences. In contrast to drug thrombolysis, intravascular thrombectomy increases the risk of additional complications, such as vascular perforation, cerebral vascular intercalation, and fracture of the latch device. This study suggests that the anterior circulation of acute cerebral infarction within 6-8 hours, the posterior circulation acute cerebral infarction in 12-14 hours of endovascular treatment has certain feasibility. The innovation of this study was that the patients who were selected were all patients with cerebral angiography, which confirmed the complete occlusion of the target vascular disease, and the cerebral vascular stent was taken and combined with the intravenous injection. The deficiency of this study is that the number of cases included is less, and a larger sample size test will be further confirmed in the future.

\section{References}

1. Qureshi AI, Siddiqui AM, Kim SH, Hanel RA, Xavier AR, et al. (2004) Reocclusion of recanalized arteries during intra-arterial thrombolysis for acute ischemic stroke. $A J N R$ Am J Neuroradiol 25: 322-328. [Crossref]

2. Oh HG, Chung PW, Rhee EJ (2015) Increased Risk for Intracranial Arterial Stenosis in Subjects with Coronary Artery Calcification. Stroke 46: 151-156.

3. Janjua N, Alkawi A, Suri MF, Qureshi AI (2008) Impact of arterial reocclusion and distal fragmentation during thrombolysis among patients with acute ischemic stroke. AJNR Am J Neuroradiol 29: 253-258. [Crossref] 
4. Siebler M, Hennerici MG, Schneider D, von Reutern GM, Seitz RJ, et al. (2011) Safety of Tirofiban in acute Ischemic Stroke: the SaTIS trial. Stroke 42: 2388-2392. [Crossref]

5. Saver JL, Goyal M, Bonafe A, Diener HC, Levy EI (2015) Stent-Retriever Thrombectomy after Intravenous t-PA vs. t-PA Alone in Stroke. $N$ Engl J Med 372: 2285-2295

6. Berkhemer OA, Fransen PS, Beumer D, van den Berg LA, Lingsma HF, et al. (2015) A Randomized trial of intraarterial treatment for acute ischemic stroke. New Engl JMed 372: 394. [Crossref]

7. Kim JW, Jeon P, Kim GM, Bang OY, Byun HS, et al. (2012) Local intraarterial tirofiban after formation of anterograde flow in patients with acute ischemic stroke: preliminary experience and short term follow-up results. Clin Neurol Neurosurg 114: 1316-1319. [Crossref]

8. Tianli J, Lie M, Xinmin F (2017) Comparison of clinical curative effect between routine time window and extended time window dynamic and intravenous thrombolytic therapy for acute cerebral infarction. Practical Journal of Cardiovascular and Pulmonary Diseases 25.
9. Seifert M, Ahlbrecht A, Dohmen C, Spuentrup E, Moeller-Hartmann W (2011) Combined interventional stroke therapy using intracranial stent and local intraarterial thrombolysis(LIT). Neuroradiology 53: 273-282. [Crossref]

10. Venker C, Stracke P, Berlit P, etal. (2010) New options in the therapeutic management of a cute ischaemic stroke. Good results with combined i.v. And i.a. Lysis and mechanical thrombectomy. Fortschr Neurol Psychiatr 78: 652 -657.

11. Demchuk AM, Goya 1M, Menon BK, Eesa M, Ryckborst KJ, et al. (2015) Endovascular treatment for Small Core and Anterior Circulation Proximal occlusion with Emphasis on minimizing CT to recanalization times (ESCAPE) trial: methodology. Int $J$ Stroke 10: 429-438. [Crossref]

12. Saver J, Jahan R, Levy E, Jovin TG, Baxter B, et al. (2012) Solitaire flow restoration device versus the Merci Retriever in patients with acute ischaemic stroke(SWIFT) A randomised, parallel-group, non-inferiority trial. Lancet 380: 1241-1249. [Crossref]

13. Almekhlafi MA, Menon BK, Freiheit EA, Demchuk AM, Goyal M (2013) A metaanalysis of observational intra-arterial stroke the rapystudies using the Merci device, penumbra system and retrievable stents. AmJ Neuroradiol 34: 140-145.

Copyright: $(2018$ Xinmin F. This is an open-access article distributed under the terms of the Creative Commons Attribution License, which permits unrestricted use, distribution, and reproduction in any medium, provided the original author and source are credited. 